\title{
SITUAÇÃO E PERSPECTIVAS DA FRUTICULTURA DE CLIMA TEMPERADO NO BRASIL ${ }^{1}$
}

\author{
JOSÉ CARLOS FACHINELLO², MATEUS DA SILVEIRA PASA ${ }^{3}$, \\ JULIANO DUTRA SCHMTIZ3, DÉBORA LEITZKE BETEMPS ${ }^{3}$
}

RESUMO - A fruticultura está presente em todos os estados brasileiros e, como atividade econômica, envolve mais de cinco milhões de pessoas que trabalham de forma direta e indireta no setor. O Brasil é o terceiro maior produtor mundial de frutas, com colheita em torno de 40 milhões de toneladas ao ano, mas participa com apenas $2 \%$ do comércio global do setor, o que demonstra o forte consumo interno (ANUÁRIO BRASILEIRO DE FRUTICULTURA, 2010). A área plantada com plantas frutíferas no Brasil está distribuída em 1.034.708 ha com frutas tropicais, 928.552 ha com frutas subtropicais e 151.732 ha com espécies de clima temperado. Dentre as frutas de clima temperado, destaca-se a produção de uvas de mesa e viníferas (81.355 ha); maçãs (38.205 ha); pêssegos, ameixas e nectarinas (19.043 ha); caqui (8.638 ha); morango, amora, framboesa, mirtilo (3.560 ha); figo (2.886 ha); pera (1.394 ha) e marmelo (211 ha). Mesmo com uma área inferior em relação às espécies de clima tropical e subtropical, as frutas de clima temperado têm uma importância socioeconômica destacada em diversas regiões do Brasil, principalmente nos Estados do Rio Grande do Sul, Santa Catarina, Paraná, São Paulo, Minas Gerais e o Vale do São Francisco, seja como cultivo in natura, agroindústria e/ou agroturismo. Para que ocorra a produção de frutas de qualidade nas regiões de clima temperado no Brasil, é necessário o desenvolvimento de programas de melhoramento genético e/ou estudos de manejo e controles sobre a fisiologia das plantas para adaptá-las às condições de inverno ameno e com oscilação de temperaturas, muito frequentes nas principais regiões produtoras brasileiras. Os verões longos e excesso de precipitação ocasionam muitas doenças e pragas, obrigando muitas vezes ao excesso de tratamentos fitossanitários. O manejo dos pomares com a produção integrada de frutas está possibilitando a produção de qualidade e, ao mesmo tempo, reduzindo o impacto ambiental da atividade no setor. Os desafios estão relacionados à adaptação das espécies às mudanças climáticas, à necessidade de se reduzir o uso de agrotóxicos e insumos, aos manejo pré e pós-colheita realizados nas frutas, logística para atender aos diferentes mercados, controle de doenças e pragas e aos programas de melhoramento genético para atender às novas demandas de cada uma das espécies de clima temperado.

Termos para indexação: Brasil, produção de frutas, exportação, importação, consumo interno.

\section{SITUATION AND PERSPECTIVES OF TEMPERATE FRUIT CROPS IN BRAZIL}

ABSTRACT- Fruticulture is present in all Brazilian states, and as economic activity, involves around five million people, directly and indirectly. Brazil is the third largest fruit producer, with output of around 40 million tons a year, but has only $2 \%$ of global trade industry, which demonstrates the high domestic consumption. The Brazilian fruit growing area is approximately 1.9 million hectares of which 1,034,708 hectares of tropical fruits, 928,552 ha of subtropical fruits and 135,857 ha of temperate species. Among the fruits of temperate climate, are table and wine grapes $(81,677 \mathrm{ha})$, apples $(39,081 \mathrm{ha})$, peaches, plums and nectarines $(19,102$ ha), persimmons ( $8,740 \mathrm{ha})$, strawberries, blackberries, raspberries, blueberries $(3,560 \mathrm{ha})$, figs $(3,072 \mathrm{ha})$, pears $(1,404 \mathrm{ha})$ and quinces $(211 \mathrm{ha})$. Even with a smaller area than the species of tropical and subtropical climate, the temperate fruits have a social importance, highlighted in several regions of southern Brazil, which corresponds to the states of Rio Grande do Sul, Santa Catarina, Parana, of southeastern Brazil, Sao Paulo and Minas Gerais, and in the São Francisco Valley region, in northeasten Brazil, either as fresh crops, agribusiness and/or agrotourism. Brazilian exports of fruits in recent years have been very positive, both in volume and in value. In 1998 Brazil exported 294,222 tons of fruits, whereas in 2008 exported 887,978 tons, representing a $201.8 \%$ increase in export volume. The main fruits that contributed to this significant increase were melon, mango, banana, apple and grape, with an increase in export volume between 1998 and 2008 of 226, 242, 91, 948 and $1766 \%$ respectively. The production of quality fruits in the temperate regions of southeastern Brazil

\footnotetext{
${ }^{1}$ Palestra Sinfruit 097 - Simpósio Internacional de Fruticultura - Avanços na Fruticultura (17 a 21 Outubro)

${ }^{2}$ Professor Titular de Fruticultura da FAEM/UFPEL, Pelotas- RS, Brasil. e-mail: jfachi@ufpel.tche.br

${ }^{3}$ M.Sc em Fruticultura da FAEM/UFPEL, Pelotas-RS, Brasil.
} 
needs genetic and breeding programs and studies on agricultural management, as well as on plant physiology to adapt them to the mild winter and to the range of temperatures, very frequent in major Brazilian regions. The long summers and precipitation excess cause many diseases and pests, which often requires pesticide treatments in excess. The management of the orchards with integrated fruit production is enabling the production of high quality fruits and at the same time is reducing the environmental impact of the activity. The challenges are related to climate changes, the necessity of pesticide use reduction and supplies, the fruit handling pre-and post-harvest, and to the need for logistics to suit the different markets, the control of pests and diseases and the breeding programs, in order to meet the new demands of each temperate species.

Index terms: Brazil, fruit production, exportation, importation, domestic consumption.

\section{INTRODUÇÃO}

O Brasil é o terceiro maior produtor mundial de frutas, com uma produção de 40 milhões de toneladas ao ano, mas participa com apenas $2 \%$ do comércio global do setor, o que demonstra o forte consumo interno (ANUÁRIO BRASILEIRO DE FRUTICULTURA, 2010). A área plantada com frutas no País é de aproximadamente 1,9 milhão de hectares. As frutas que mais contribuem no volume total da produção brasileira são a Laranja, Banana, Abacaxi, Melancia e Mamão, que, juntas, somam aproximadamente 30 milhões de toneladas. Nesse contexto, a produção de frutas de clima temperado representa apenas 7,5\% (3,02 milhões ton) (Tabela 1) e $8 \%$ (151.732 ha) da área total cultivada com frutíferas no Brasil (Tabela 2) (IBGE,2009); no entanto, são responsáveis por aproximadamente 37 $\%$ do valor total das exportações de frutas do País. Esses valores demonstram a grande importância da fruticultura de clima temperado, principalmente nas exportações, as quais são necessárias para manter a balança comercial positiva, ou seja, com mais exportações do que importações.

As frutíferas de clima temperado estão distribuídas em 11 dos 26 estados brasileiros (Figura 1). O Rio Grande do Sul responde por aproximadamente 49,3 \% do total produzido no País, seguido de Santa Catarina (23,2 \%), São Paulo (10,3 \%), Paraná (6,2 $\%$ ), Pernambuco (5,3\%), Bahia (3,0\%) e Minas Gerais $(1,8 \%)$ (Tabela, 3$)$. Além desses, as frutíferas de clima temperado estão presentes no Estado do Rio de Janeiro, Paraíba, Mato Grosso e Goiás.

A fruticultura participa diretamente na economia do País através do valor das exportações e mercado interno, e pode-se salientar ainda a importância no caráter econômico-social, uma vez que está presente em todos os estados brasileiros, sendo responsável pela geração de 5,6 milhões de empregos diretos, o equivalente a $27 \%$ do total da mão de obra agrícola do País. O setor de fruticultura está entre os principais geradores de renda, emprego e de desenvolvimento rural do agronegócio nacional. A atividade frutícola possui elevado efeito multiplicador de renda e, portanto, com força suficiente para dinamizar economias locais estagnadas e com poucas alternativas de desenvolvimento (BUAINAIN; BATALHA, 2007).

O aumento da área cultivada e a produção de frutas de clima temperado têm crescido no Brasil. Isso ocorreu principalmente devido à modernização e melhor gestão da propriedade rural e de todos os fatores de produção, à adoção de tecnologias de baixo impacto ambiental, visando à qualidade, segurança do produto e preservação do meio ambiente e, deste modo, atendendo às exigências do mercado consumidor brasileiro e transpondo as rigorosas barreiras fitossanitárias impostas pelos países importadores.

Nesse contexto, foi implementado no Brasil, a partir de 1998, o sistema de produção integrada de frutas (PIF), destacando-se pela credibilidade conferida às frutas produzidas. Esse sistema de produção surgiu com o intuito de atender à necessidade de se obter um sistema de produção agrícola sustentável que pudesse proporcionar segurança ao produtor e ao consumidor, com rentabilidade. Além disso, a adoção de novas tecnologias de manejo cultural e a proteção das plantas possibilitaram incrementos significativos em produtividade das principais frutíferas de clima temperado. Muitas dessas tecnologias foram e são continuamente desenvolvidas tanto pelas instituições públicas quanto pela iniciativa privada, sempre com o objetivo de propiciar aos fruticultores alternativas e soluções para os principais problemas, fomentando o sucesso de toda a cadeia produtiva da fruticultura de clima temperado.

\section{SITUAÇÃO E PERSPECTIVA DAS FRUTAS DE CLIMA TEMPERADO}

As exportações brasileiras de frutas frescas passaram por um período negativo de cinco anos, entre 1994 e 1999, em que o valor importado foi maior do que o exportado, resultando em déficit na comercialização de frutas (Figura 2). Essa situação mudou a partir de 1999, onde o valor exportado passou a ser maior do que o valor importado e, a partir 
daí, o País vem somando sucessivos resultados positivos com as exportações de frutas frescas (Figura 2). No ano de 2008, o País exportou aproximadamente 888.000 ton de frutas, o que significou U\$S 723 milhões (FAOSTAT, 2011), dos quais as frutas de clima temperado representaram 197.964 ton (Tabela 4) e U\$S 267.382 milhões (Tabela 5).

Dessa forma, é notável a importância da fruticultura de clima temperado para o desenvolvimento da fruticultura nacional. As frutas mais produzidas são, em ordem decrescente, uva, maçã, pêssego, caqui, figo, pera e marmelo, sendo que o crescimento total no período de 1999-2009 foi de 43,5\% (Tabela 1 ), o que corresponde a $4,35 \%$ ao ano. Fato importante a ser observado é que esse incremento geral em produção ocorreu em função principalmente de incremento na produtividade, uma vez que, para o mesmo período, a área colhida cresceu $24,14 \%$ (Tabela 2), ou seja, uma taxa de $2,41 \%$ ao ano, metade do crescimento observado na produção.

\section{VIDEIRA}

A produção de uvas representa $45 \%$ da produção total e $64 \%$ das exportações das frutas de clima temperado. No período de 1999 a 2009, a produção aumentou 433.990 ton $(46,59 \%$ ) e a área 21.976 ha (37,01\%) (Tabelas 1 e 2).

A produção de uvas no Brasil é diferenciada de acordo a região de cultivo: no Sul, predomina o cultivo de uvas americanas e híbridas para fabricação de sucos e vinhos, e nas outras regiões, o cultivo de uvas americanas e europeias de mesa, tanto para o mercado interno, como para exportação. Os principais estados produtores de uva e suas respectivas participações na produção total são apresentados na Tabela 3. A produtividade média nesse mesmo período permaneceu praticamente constante, variando no máximo em 2 ton ha-1 (Tabela 6). No entanto, em algumas regiões, a produtividade é significativamente acima da média, como ocorre no Vale do São Francisco, em que a média é de 25 ton ha-1 (IBGE, 2009), explicando deste modo o maior crescimento da produção $(46,59$ \%) em relação ao aumento da área total $(37,01 \%)$. Esses resultados são compatíveis com o crescimento na exportação de uvas, representada principalmente pela uva de mesa, que cresceu, entre 1998 e 2008, 948,48 \% em quantidade e $2.844,46 \%$ em valor (Tabelas 4 e 5 ).

A tendência é que o Brasil, nas regiões quentes, continue a especializar a sua produção em termos de uvas de mesa sem sementes para atender ao mercado internacional, e na região Sul, aumente a área cultivada de uvas viníferas em detrimento ao cultivo de uvas americanas e híbridos.

Grande parte desse sucesso é devido à produção de uvas no Vale do São Francisco, pois, nessa região, o clima predominantemente quente e seco durante grande parte do ano, a infraestrutura de irrigação e a mão de obra disponível propiciam as condições favoráveis para o desenvolvimento desta cultura. Além disso, a produção regional, voltada principalmente para o mercado externo, impulsiona investimentos em técnicas de manejo da cultura, para cada vez mais melhorar a qualidade e a produtividade dos parreirais. A irrigação trouxe muitas vantagens à agricultura do Vale do São Francisco, entre as quais se destacam a regularidade da produção e o aumento do rendimento da terra, permitindo ganhos expressivos de produção e de renda. Com a regularidade da produção, a região consegue competir em boas condições no mercado internacional, obtendo frutos de melhor qualidade (BUAINAIN; BATALHA, 2007). Nesta condição de clima tropical, é possível planejar os períodos de colheita e assim atender às demandas internacionais com uvas sem sementes, quando os preços atingem os valores mais elevados.

\section{MACIEIRA}

A cultura da macieira teve um crescimento na área colhida de 33,79 \% (Tabela 2), 30,41\% na produção (Tabela 1), 948,48 \% na quantidade exportada (Tabela 4) e 1.328,07 \% no valor exportado (Tabela 5), nos últimos 10 anos. Por outro lado, as importações, em quantidades e valores, diminuíram, no período, $56,38 \%$ e 13,19\%, respectivamente (Tabelas 7 e 8). Esses resultados reforçam a tendência que vem ocorrendo desde o início da pomicultura no País e revelam o grande potencial exportador do Brasil. Os fatores responsáveis por esse grande desenvolvimento da cultura da macieira devem-se ao desenvolvimento das tecnologias utilizadas nos cultivos, pela logística implantada, pela definição de cultivares (Gala, 58\% e Fuji, 36\%) e clones capazes de atender às exigências dos consumidores.

Dessa forma, além de medidas de incentivo governamental ao cultivo a partir dos anos 70 , centros de pesquisa e extensão rural, visando ao melhoramento, adaptação, nutrição mineral, manejos fitotécnicos e fitossanitários da cultura, tecnologia de armazenamento pós-colheita com uso de atmosfera controlada, permitiram ao País passar de importador, principalmente da Argentina, para exportador da fruta em poucos anos. Pois, uma década após iniciar o cultivo da macieira em escala comercial, as importações brasileiras de maçã começaram a se reduzir, e hoje o País é considerado autossuficiente.

A expectativa é que os cultivos continuem a crescer em taxas de $3,37 \%$ ao ano e que cada vez se 
concentre a produção nos clones de Gala e Fuji.

\section{FRUTAS DE CAROÇO}

Neste grupo de frutas de clima temperado, predomina o pêssego, seguido pela ameixa e nectarina, sendo que a área com pessegueiro representa mais de $80 \%$ da área cultivada. O Brasil não produz cerejas, amêndoas e damasco.

\section{PESSEGUEIRO}

A produção brasileira de pêssegos apresenta características diferentes de acordo com a região: no Rio Grande do Sul, predomina o cultivo de frutas para indústria e dupla finalidade, e nas demais regiões, predomina o cultivo de pêssegos, ameixas e nectarinas para mesa.

No período de 1999 a 2009, a produção de pêssegos aumentou em $64,69 \%$, e a área colhida diminuiu em 15,39\% (Tabelas 1e 2). Esses resultados ocorreram principalmente em função do incremento na produtividade média, que passou de $5.833 \mathrm{~kg}$ ha-1 em 1999, para $11.355 \mathrm{~kg}$ ha-1 em 2009, ou seja, incrementou 94,67 \% (Tabela 6). Assim, pode-se explicar o maior crescimento da produção em relação ao decréscimo da área total. Os principais estados produtores de pêssego são, em ordem decrescente, RS (65,1\%); SP (14,0\%); MG (11,8\%); PR $(7,5 \%)$ e SC (1,6\%) (Tabela 3). Os valores das quantidades de importações com frutas de caroço aumentaram para cereja, manteviveram-se estáveis para o pêssego e diminuíram de forma significativa para ameixa, nectarina e damascos. Essa mudança de comportamento nos volumes importados deve-se à política brasileira de incentivo ao cultivo de plantas frutíferas, ao trabalho de pesquisa e à valorização das frutas pelo consumidor.

As principais ações de pesquisa com frutas de caroço envolvem a criação, adaptação de cultivares que sejam resistentes a doenças, produzam frutas de qualidade e atenda ao gosto do consumidor em relação à coloração da epiderme, equilíbrio acidez/ açúcar e tamanho, além de apresentarem resistência ao transporte e armazenamento.

A tendência é que haja uma estabilização na área cultivada e que diminua o cultivo de pêssegos para indústria, dando lugar às frutas de dupla finalidade e, principalmente, frutas de mesa para outras regiões do País.

\section{AMEIXEIRA}

A ameixa ocupa a $3^{\mathrm{a}}$ posição nas importações de frutas frescas, porém, entre 1998 e 2008 , houve redução de $29,62 \%$ no volume e $19,18 \%$ no valor das importações (Tabelas 7 e 8). Por outro lado, no mesmo período, esta fruta passou a fazer parte das exportações do País de forma pouco significativa e muito instável. As importações são oriundas da Argentina (47,3\%), Espanha (25\%), Chile (21,3 $\%)$, USA (3,3\%), Itália (2,2\%) e Portugal (0,9\%) (FAOSTAT, 2011). A área ocupada com ameixeira no Brasil é de 4.515 ha e uma produção de 63.381 ton/ ano, sendo os principais estados produtores no ano de 2009, em ordem decrescente, Santa Catarina, São Paulo, Paraná, Rio Grande do Sul e Minas Gerais, com participação percentual na produção em 23,77 ; 23,$01 ; 21,86 ; 21,30$ e $10,06 \%$, respectivamente com ameixas do grupo asiático. Em Santa Catarina, maior produtor, com 936 ha, existe um grande número de municípios que cultivam ameixas, mas as grandes áreas estão concentradas na região do Rio do Peixe. Em regiões com maior quantidade de frio, como acontece em São Joaquim-SC, e Vacaria, no Rio Grande do Sul, é possível cultivar ameixas de origem europeia.

A perspectiva é que o aumento no cultivo desta espécie ocorra em regiões mais frias do Sudeste, principalmente para substituir as importações que ocorrem com esta espécie.

A perspectiva é que ocorra um aumento no cultivo de ameixas nas regiões mais frias do Sudeste, principalmente para atender à demanda crescente $\mathrm{e}$ às importações anuais.

\section{CAQUIZEIRO}

Dentre as frutas de clima temperado, o caquizeiro foi a que apresentou maior crescimento nos últimos anos. De 1999 a 2009, a produção cresceu $167,65 \%$, e a área colhida, $48,42 \%$ (Tabelas 1 e 2). Além disso, as exportações cresceram muito nesse período, aumentando de 155 (1998) para 1.724 ton (2008), ou seja, crescimento de 1.012,26 \%. Em contrapartida, nesse mesmo período, foi a fruta que apresentou a maior redução tanto no volume $(-88,73$ $\%$ ) quanto em valor importado (-76,43\%) (Tabelas 7 e 8). O sucesso dessa cultura é devido à possibilidade de obtenção de boa produtividade, com pouca utilização de insumos, uma vez que o caquizeiro apresenta relativa rusticidade em relação ao ataque de pragas e doenças, adaptação aos diversos tipos de clima e possibilidade de exportação. Contudo, alguns problemas ainda impedem o crescimento dessa cultura, como, por exemplo, a coincidência de colheita da cultivar Fuyu nos principais estados produtores, fato que requer a adoção de medidas de manejo pré 
e pós-colheita para, desta maneira, controlar a oferta e, consequentemente, evitar que ocorram variações negativas no preço de venda.

A perspectiva é que o aumento de cultivo continue, uma vez que se trata de uma espécie interessante para diversificação nos pomares, exportação e pela aceitação das cultivares do grupo sem adstringência.

\section{PEREIRA}

O cultivo de peras no País ainda é pouco expressivo, representando apenas $0,5 \%$ do total de frutas de clima temperado produzido no País. A produção dessa fruta ao longo dos últimos anos decresceu 9,82 \% (Tabela 1), e a área colhida, 28,99 $\%$ (Tabela 2). Além disso, destaca-se como a fruta fresca importada em maior quantidade, ou seja, aproximadamente 140.000 ton (Tabela 6), apresentando crescimento de $63,5 \%$ no valor importado, no período de 1998-2008. Os principais exportadores de pera para o Brasil são a Argentina, Portugal e USA, sendo responsáveis por $113(82 \%), 10(7 \%)$ e $9(6.5 \%) \mathrm{mil}$ ton, respectivamente (FAO, 2011). Logo, é possível constatar que a cultura da pereira representa uma importante oportunidade de mercado. No entanto, problemas relacionados com o vigor da plantas, tipo de porta-enxerto, abortamento floral, insuficiência de frio hibernal, falta de cultivares adaptadas às condições edafoclimáticas, dentre outros, impedem a expansão da cultura no País.

Os aumentos na área cultivada dependem do surgimento de novas cultivares e de trabalhos de pesquisa com o manejo da planta que assegurem a produção contínua desta espécie em locais de invernos com grande oscilação de temperatura.

\section{FIGUEIRA}

A cultura da figueira também apresentou crescimento significativo nos últimos anos, incrementando em $45,72 \%$ o volume produzido (Tabela 1), $116,16 \%$ na quantidade e $404,03 \%$ no valor exportado. Os principais países importadores do figo brasileiro são Holanda (31 \%), França (28 \%), Alemanha (18\%) e Reino Unido (10\%) (FAOSTAT, 2011). A expansão da cultura da figueira foi estimulada pela possibilidade de aproveitamento do figo na indústria, crescimento na exportação, facilidade de cultivo e adaptação a diferentes tipos de clima e a precocidade de produção. Ademais, com o desenvolvimento de políticas públicas de produção integrada, houve a possibilidade de certificação da produção, pelo protocolo internacional (GlobalGap), habilitando as exportações para a Europa. Além disso, outro passo importante foi a reorganização do modelo de colheita e casas de embalagens, as melhorias do processo de seleção do fruto e a apresentação.

Uma das limitações da cultura é a concentração do cultivo na cultivar Roxo de Valinhos, perecibilidade e a concorrência com outras frutas nos mercados interno e externo.

\section{QUIVIZEIRO}

A cultura do quivi está concentrada principalmente na região Sul do País, porém a produção ainda é bastante restrita, devido a limitações tecnológicas que permitam o avanço da cultura. Dessa forma, torna-se evidente a necessidade de importação dessa fruta para suprir a demanda do mercado interno. Mesmo assim, o cultivo do quivi apresentou avanços na produção, que podem ser notados através da redução de 54,33 $\%$ no volume e $30,35 \%$ no valor importado, no período de 1998-2008 (Tabelas 7 e 8). As principais regiões de cultivo dessa fruta são o Rio Grande do Sul, Santa Catarina e Paraná que, juntas, respondem por aproximadamente $80 \%$ da fruta produzida. O avanço dessa cultura vem ocorrendo principalmente pela sua característica de rusticidade, pela adaptação às regiões de cultivo, pela demanda interna, uma vez que aproximadamente metade da fruta consumida no País ainda é importada, e pelo potencial para exportações de frutas de alta qualidade.

A ampliação do cultivo e a possibilidade de suprir as importações anuais dependem de políticas públicas de apoio à introdução e adaptação de novas cultivares e da aposta pelos produtores nesta espécie.

\section{MARMELEIRO}

A cultura do marmeleiro registrou, nos últimos 10 anos, decréscimo de $85,01 \%$ na área colhida (Tabela 2) e $80,02 \%$ na produção (Tabela 1). Os estados que mais contribuem para a produção são, respectivamente, Minas Gerais, Bahia e Rio Grande do Sul.

As causas prováveis desse pequeno interesse devem-se à utilização pouco nobre do marmelo, como matéria-prima industrial e no incipiente consumo in natura. Por causa da baixa produção nacional, a quantidade de frutas que chegam ao mercado pode ser comercializada a preços atraentes. Além disso, é uma alternativa na diversificação produtiva de propriedades rurais, podendo-se agregar valor ao produto em confecções de doces.

A tendência é que esta espécie restrinja ainda mais a área cultivada em todo o País, dada a grande oferta de outras frutas no mercado o ano todo. 


\section{PEQUENAS FRUTAS DE CLIMA TEMPERADO}

No contexto da produção de frutas de clima temperado, as pequenas frutas ainda são pouco expressivas, mas verificam-se avanços. As principais frutíferas representantes desse grupo são o morangueiro, a framboesa, a amora-preta e o mirtilo. O morango é a fruta mais representativa desse grupo, com produção de aproximadamente 105.000 toneladas, distribuídos em quatro mil hectares, sendo que o interesse pelo cultivo do morango é justificado pela alta rentabilidade da cultura, o amplo conhecimento e a aceitação da fruta pelo consumidor e pela diversidade de opções de comercialização e processamento do morango (polpa, sorvetes, geleias, compotas e sucos). O cultivo está concentrado nos Estados de Minas Gerais (41,4\%), Rio Grande do Sul (25,6\%), São Paulo (15,4\%), Paraná (4,7\%) e Distrito Federal (4\%) (ANUÁRIO BRASILEIRO DE FRUTICULTURA, 2005). A framboesa manteve-se estável nos últimos anos, tanto no volume exportado quanto no importado (Tabelas 4 e 6). Nesse mesmo período, a expor- tação de mirtilo evoluiu em 350,00\% (Tabela 4). O crescente interesse por essa cultura está relacionado principalmente às suas propriedades nutracêuticas. De acordo com Silveira et al. (2007), o mirtilo é uma fonte rica em água, benéfica às reações químicas e aos processos metabólicos do organismo, apresenta quantidade significativa de cálcio, comparada aos demais frutos, além de uma quantidade elevada de vitamina $\mathrm{C}$ e alto teor de polifenóis.

O cultivo da amora-preta começou a se desenvolver a partir de um programa de melhoramento genético, no qual foram criadas as primeiras cultivares brasileiras (Tupy, Guarani e Caigangue). Estima-se que a área de produção de amora-preta no Brasil seja de 150 ha, estendendo-se do Espírito Santo, Rio de Janeiro e Sul de Minas Gerais, ao sul do Rio Grande do Sul (ANTUNES et al., 2007).

A tendência é que ocorra aumento e diversificação do cultivo de frutas vermelhas, tendo estas grande apelo e utilização no mercado brasileiro; além disto, existe a perspectiva de aumento na procura para exportação destas frutas, visando a atender à entressafra do Hemisfério Norte.

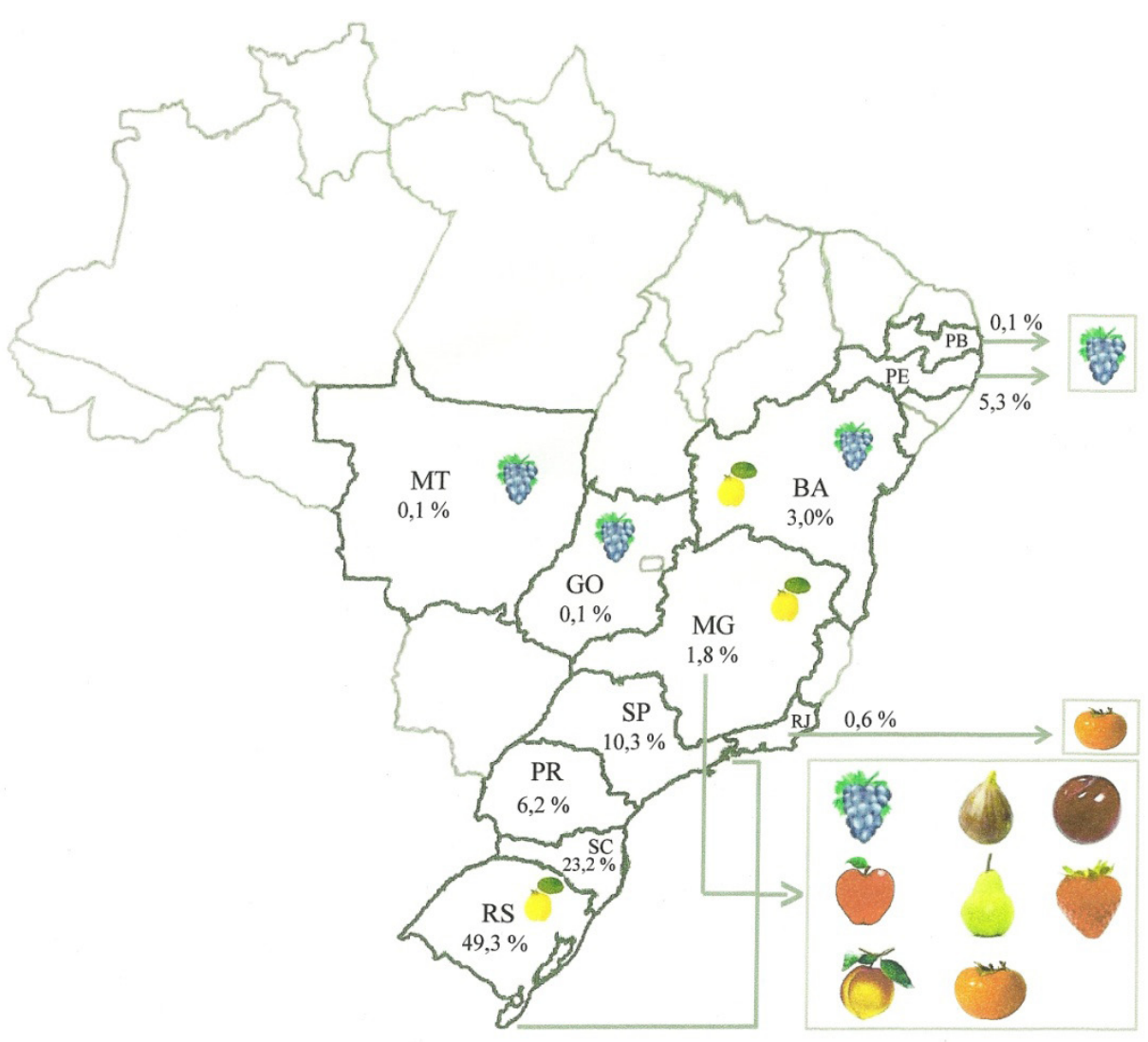

FIGURA 1 - Distribuição das frutíferas de clima temperado e participação percentual de cada estado no total produzido no Brasil. (IBGE, 2009; ANUÁRIO BRASILEIRO DE FRUTICULTURA, 2005). 


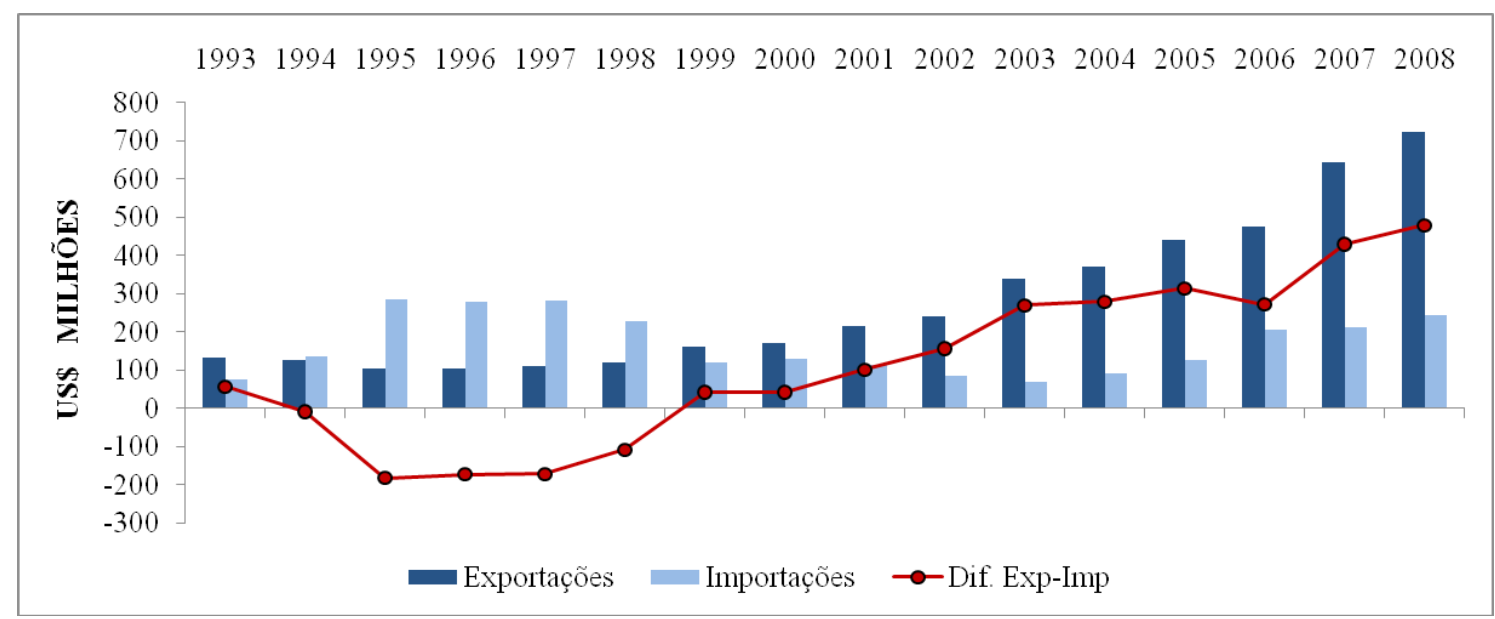

FIGURA 2 - Comparativo entre as exportações e importações brasileiras de frutas frescas no período de 1993 a 2008. FAOSTAT (2011).

TABELA 1 - Evolução da produção das principais frutíferas de clima temperado no Brasil. FAOSTAT (2011).

Produção (toneladas)

\begin{tabular}{ccccccccc} 
Ano & Uva & Maçã & Pêssego & Caqui & Figo & Pera & Marmelo & Total \\
\hline 1999 & 931.500 & 937.715 & 131.300 & 64.096 & 16.570 & 16.474 & 4.879 & 2.102 .534 \\
2000 & 1.024 .480 & 1.153 .270 & 182.460 & 63.300 & 17.207 & 16.970 & 4.600 & 2.462 .287 \\
2001 & 1.058 .490 & 716.030 & 222.616 & 105.000 & 25.981 & 21.502 & 4.204 & 2.153 .823 \\
2002 & 1.148 .650 & 857.388 & 218.292 & 141.364 & 23.921 & 19.696 & 900 & 2.410 .211 \\
2003 & 1.067 .420 & 841.821 & 220.364 & 158.131 & 25.586 & 19.790 & 1.266 & 2.334 .378 \\
2004 & 1.291 .380 & 980.203 & 235.720 & 162.288 & 26.839 & 19.894 & 1.248 & 2.717 .572 \\
2005 & 1.232 .560 & 850.535 & 235.471 & 164.849 & 23.697 & 19.746 & 1.078 & 2.527 .936 \\
2006 & 1.257 .060 & 863.019 & 199.719 & 168.274 & 26.476 & 18.161 & 910 & 2.533 .619 \\
2007 & 1.371 .560 & 1.115 .380 & 185.959 & 159.851 & 23.225 & 17.074 & 931 & 2.873 .980 \\
2008 & 1.421 .430 & 1.124 .160 & 239.149 & 173.297 & 22.565 & 17.391 & 905 & 2.998 .897 \\
2009 & 1.365 .490 & 1.222 .890 & 216.236 & 171.555 & 24.146 & 14.856 & 975 & 3.016 .148 \\
\hline Variação (\%) & 46,59 & 30,41 & 64,69 & 167,65 & 45,72 & $-9,82$ & $-80,02$ & 43,45 \\
\hline
\end{tabular}


TABELA 2 - Área colhida das principais frutíferas de clima temperado, entre os anos de 1999 e 2009 , Brasil. FAOSTAT (2011).

\begin{tabular}{ccccccccc}
\hline & \multicolumn{7}{c}{ Área colhida (ha) } \\
Ano & Uva & Maçã & Pêssego & Caqui & Figo & Pera & Marmelo & Total \\
\hline 1999 & 59.379 & 28.555 & 22.508 & 5.820 & 2.592 & 1.963 & 1.408 & 122.225 \\
2000 & 59.788 & 30.043 & 22.039 & 6.230 & 2.805 & 2.073 & 1.500 & 124.478 \\
2001 & 63.273 & 30.938 & 23.129 & 6.900 & 2.904 & 1.948 & 1.453 & 130.545 \\
2002 & 66.300 & 31.519 & 23.744 & 6.958 & 3.111 & 1.873 & 200 & 133.705 \\
2003 & 68.432 & 31.532 & 24.507 & 7.472 & 3.109 & 1.784 & 236 & 137.072 \\
2004 & 71.637 & 32.993 & 23.864 & 8.112 & 3.113 & 1.779 & 230 & 141.728 \\
2005 & 73.203 & 35.493 & 23.794 & 8.309 & 2.911 & 1.759 & 215 & 145.684 \\
2006 & 75.354 & 36.107 & 22.453 & 8.534 & 3.007 & 1.723 & 185 & 147.363 \\
2007 & 78.273 & 37.832 & 22.398 & 8.065 & 2.850 & 1.650 & 196 & 151.264 \\
2008 & 79.946 & 38.072 & 21.320 & 8.797 & 2.859 & 1.609 & 197 & 152.800 \\
2009 & 81.355 & 38.205 & 19.043 & 8.638 & 2.886 & 1.394 & 211 & 151.732 \\
\hline Variação (\%) & 37,01 & 33,79 & $-15,39$ & 48,42 & 11,34 & $-28,99$ & $-85,01$ & 24,14 \\
\hline
\end{tabular}

TABELA 3 - Participação de cada estado na produção das principais frutíferas de clima temperado. Brasil, IBGE 2009.

\begin{tabular}{lcl}
\hline \multicolumn{1}{c}{ Fruta } & $\begin{array}{c}\text { Produção } \\
\text { (ton) }\end{array}$ & \multicolumn{1}{c}{ Estado - Participação (\%) } \\
\hline Uva & 1.359 .564 & $\begin{array}{l}\text { RS (54,2); SP (13,6); PE (11,7); PR (7,5); BA (6,7); SC (5,0); MG (0,9); PB } \\
(0,1) ; \text { MT (0,1); GO (0,2) }\end{array}$ \\
Maçã & 1.222 .520 & SC (50,9); RS (45,5); PR (3,2); SP (0,1); MG (0,2) \\
Pêssego & 216.019 & RS (65,1); SP (14,0); MG (11,8); PR (7,5); SC (1,6) \\
Caqui & 171.415 & SP (50,1); RS (18,1); PR (13,6); RJ (11,1); MG (5,8); SC (1,2) \\
Morango & 105.000 & MG (41,4); RS (25,6); SP (15,4); PR (4,7); DF (4) \\
Figo & 24.098 & RS (43,0); SP (20,7); MG (20,5); SC (10,3); PR (5,5) \\
Pera & 14.856 & RS (56,8); PR (24,7); SP (10,4); MG (5,7); SC (2,5) \\
Marmelo & 895 & MG (51,4); BA (27,9); RS (20,7) \\
\hline
\end{tabular}


TABELA 4 - Evolução no volume das exportações brasileiras de frutas de clima temperado entre os anos de 1998 e 2008. FAOSTAT (2011).

\begin{tabular}{|c|c|c|c|c|c|c|c|c|c|c|c|c|}
\hline \multirow[t]{2}{*}{ Frutas } & \multicolumn{11}{|c|}{ Quantidade Exportada (Toneladas) } & \multirow{2}{*}{$\begin{array}{c}\begin{array}{c}\text { Varia- } \\
\text { ção (\%) }\end{array} \\
98-08\end{array}$} \\
\hline & 1998 & 1999 & 2000 & 2001 & 2002 & 2003 & 2004 & 2005 & 2006 & 2007 & 2008 & \\
\hline Maçã & 10.706 & 57.438 & 64.480 & 35.786 & 65.927 & 76.466 & 153.043 & 99.332 & 57.147 & 112.076 & 112.250 & 948,48 \\
\hline Uvas & 4.406 & 8.083 & 14.363 & 20.660 & 26.357 & 37.601 & 28.815 & 51.213 & 62.251 & 79.081 & 82.242 & $1.766,59$ \\
\hline Caqui & 155 & 371 & 411 & 238 & 445 & 629 & 802 & 842 & 995 & 864 & 1.724 & $1.012,26$ \\
\hline Figo & 761 & 747 & 707 & 633 & 622 & 815 & 910 & 837 & 875 & 1.599 & 1.645 & 116,16 \\
\hline Framb. ${ }^{*}$ & 50 & 39 & 43 & 64 & 60 & 58 & 65 & 63 & 61 & 60 & 53 & 6,00 \\
\hline Quivi & 0 & 31 & 0 & 13 & 35 & 8 & 41 & 10 & 3 & 4 & 22 & $2.200,00$ \\
\hline Ameixa & 0 & 7 & 0 & 5 & 20 & 5 & 17 & 0 & 0 & 0 & 19 & $1.900,00$ \\
\hline Mirtilo & 2 & 9 & 17 & 10 & 4 & 4 & 12 & 6 & 6 & 11 & 9 & 350,00 \\
\hline Total & 16.080 & 66.725 & 80.021 & 57.409 & 93.470 & 115.586 & 183.705 & 152.303 & 121.338 & 193.695 & 197.964 & $1.131,12$ \\
\hline
\end{tabular}

TABELA 5 - Valor das exportações brasileiras de frutas de clima temperado no período de 1998-2008. FAOSTAT (2011).

\begin{tabular}{lcccccccccccccc}
\hline Frutas & \multicolumn{1}{c}{ Valor exportado (1000 U\$S) } & & & \multicolumn{1}{c}{$\begin{array}{c}\text { Variação } \\
(\%)\end{array}$} \\
& 1998 & 1999 & 2000 & 2001 & 2002 & 2003 & 2004 & 2005 & 2006 & 2007 & 2008 & $98-08$ \\
\hline Uvas & 5.823 & 8.614 & 14.618 & 21.563 & 33.789 & 59.939 & 52.755 & 107.276 & 118.432 & 169.696 & 171.456 & $2.844,46$ \\
Maçã & 5.667 & 30.153 & 30.757 & 18.139 & 31.403 & 37.834 & 72.550 & 45.771 & 31.916 & 68.618 & 80.929 & $1.328,07$ \\
Figo & 1.438 & 1.535 & 1.269 & 1.086 & 1.093 & 1.674 & 2.109 & 2.215 & 2.853 & 6.580 & 7.248 & 404,03 \\
Caqui & 197 & 285 & 417 & 190 & 416 & 562 & 907 & 878 & 1.466 & 2.061 & 7.201 & $3.555,33$ \\
Framb. & 363 & 276 & 249 & 372 & 307 & 340 & 416 & 424 & 738 & 786 & 386 & 6,34 \\
Mirtilo & 23 & 83 & 110 & 69 & 24 & 29 & 100 & 51 & 72 & 168 & 103 & 347,83 \\
Quivi & 0 & 24 & 0 & 11 & 20 & 3 & 25 & 6 & 1 & 2 & 42 & $4.200,00$ \\
Ameixa & 0 & 5 & 0 & 5 & 22 & 2 & 54 & 0 & 0 & 0 & 17 & $1.700,00$
\end{tabular}

$\begin{array}{lllllllllllll}\text { Total } & 13.511 & 40.975 & 47.420 & 41.435 & 67.074 & 100.383 & 128.916 & 156.621 & 155.478 & 247.911 & 267.382 & 1.878,99\end{array}$

*Framb.: framboesa 
TABELA 6 - Evolução da produtividade das principais frutíferas de clima temperado no Brasil. FAOSTAT (2011).

\begin{tabular}{lcccccccccccc}
\hline \multicolumn{1}{c}{ Fruta } & \multicolumn{1}{c}{ Produtividade $\left(\mathrm{kg} \mathrm{ha}^{-1}\right)$} & & & & Média \\
& 1999 & 2000 & 2001 & 2002 & 2003 & 2004 & 2005 & 2006 & 2007 & 2008 & 2009 & $98-08$ \\
\hline Maçã & 32.839 & 38.387 & 23.144 & 27.202 & 26.697 & 29.709 & 23.963 & 23.902 & 29.482 & 29.527 & 32.009 & 28.806 \\
Caqui & 11.013 & 10.161 & 15.217 & 20.317 & 21.163 & 20.006 & 19.840 & 19.718 & 19.820 & 19.700 & 19.861 & 17.892 \\
Uva & 15.687 & 17.135 & 16.729 & 17.325 & 15.598 & 18.027 & 16.838 & 16.682 & 17.523 & 17.780 & 16.784 & 16.919 \\
Pêssego & 5.833 & 8.279 & 9.625 & 9.194 & 8.992 & 9.878 & 9.896 & 8.895 & 8.302 & 11.217 & 11.355 & 9.224 \\
Pera & 8.392 & 8.186 & 11.038 & 10.516 & 11.093 & 11.183 & 11.226 & 10.540 & 10.348 & 10.809 & 10.657 & 10.362 \\
Figo & 6.393 & 6.134 & 8.947 & 7.689 & 8.230 & 8.622 & 8.141 & 8.805 & 8.149 & 7.893 & 8.367 & 7.942 \\
Marmelo & 3.214 & 3.067 & 3.067 & 4.500 & 5.364 & 5.426 & 5.014 & 4.919 & 4.750 & 4.594 & 4.621 & 4.412 \\
\hline
\end{tabular}

TABELA 7 - Evolução do volume das importações brasileiras de frutas de clima temperado entre os anos de 1998 e 2008. FAOSTAT (2011).

Quantidade Importada (Toneladas)

\begin{tabular}{|c|c|c|c|c|c|c|c|c|c|c|c|c|}
\hline Ano & Pera & Maçã & Ameixa & P./N. ${ }^{*}$ & Uvas & Quivi & Cereja & Dam. ${ }^{*}$ & Caqui & Marm. ${ }^{*}$ & Framb. ${ }^{*}$ & Total \\
\hline 1998 & 142.127 & 126.186 & 26.097 & 15.924 & 26.492 & 17.033 & 1.396 & 363 & 2.289 & 125 & 8 & 358.040 \\
\hline 1999 & 110.925 & 66.377 & 15.631 & 7.537 & 8.599 & 8.956 & 1.032 & 123 & 717 & 169 & 2 & 220.068 \\
\hline 2000 & 101.726 & 44.034 & 14.665 & 8.209 & 9.912 & 10.391 & 1.100 & 176 & 1.549 & 145 & 1 & 191.908 \\
\hline 2001 & 117.644 & 65.921 & 16.088 & 7.858 & 7.457 & 9.369 & 1.031 & 170 & 366 & 101 & 0 & 226.005 \\
\hline 2002 & 92.473 & 53.487 & 16.385 & 8.994 & 11.039 & 7.244 & 960 & 133 & 168 & 30 & 1 & 190.914 \\
\hline 2003 & 62.874 & 42.363 & 13.523 & 7.167 & 7.612 & 4.241 & 631 & 148 & 142 & 33 & 0 & 138.734 \\
\hline 2004 & 75.943 & 42.478 & 13.072 & 7.477 & 6.072 & 5.299 & 1.131 & 174 & 93 & 96 & 1 & 151.836 \\
\hline 2005 & 102.558 & 67.510 & 19.332 & 13.085 & 8.387 & 6.964 & 1.727 & 229 & 198 & 109 & 4 & 220.103 \\
\hline 2006 & 124.704 & 77.741 & 22.464 & 19.427 & 12.106 & 6.450 & 1.285 & 304 & 166 & 224 & 4 & 264.875 \\
\hline 2007 & 137.355 & 68.574 & 24.323 & 17.667 & 15.550 & 8.210 & 2.025 & 380 & 256 & 84 & 3 & 274.427 \\
\hline 2008 & 139.778 & 55.042 & 18.368 & 15.890 & 12.565 & 7.779 & 2.235 & 298 & 258 & 110 & 3 & 252.326 \\
\hline V.(\%) & $-1,65$ & $-56,38$ & $-29,62$ & $-0,21$ & $-52,57$ & $-54,33$ & 60,10 & $-17,91$ & $-88,73$ & $-12,00$ & $-62,50$ & $-29,53$ \\
\hline
\end{tabular}

*P./N.:pêssego/ nectarina; Dam.: damasco; Marm.: marmelo; Framb.: framboesa e; V.: variação 
TABELA 8 - Valor das importações brasileiras de frutas de clima temperado no período de 1998-2008. FAOSTAT (2011).

\begin{tabular}{|c|c|c|c|c|c|c|c|c|c|c|c|c|}
\hline \multirow[t]{2}{*}{ Frutas } & \multicolumn{11}{|c|}{ Valor Importado (1000 U\$S) } & \multirow{2}{*}{$\begin{array}{c}\text { Var. } \\
(\%) \\
98-08\end{array}$} \\
\hline & 1998 & 1999 & 2000 & 2001 & 2002 & 2003 & 2004 & 2005 & 2006 & 2007 & 2008 & \\
\hline Pera & 73.821 & 52.181 & 56.626 & 49.516 & 34.756 & 29.229 & 42.590 & 54.016 & 88.848 & 98.005 & 120.624 & 63,40 \\
\hline Maçã & 55.433 & 27.183 & 23.947 & 29.234 & 17.957 & 15.764 & 19.893 & 30.044 & 48.494 & 42.547 & 48.119 & $-13,19$ \\
\hline Ameixa & 26.580 & 12.624 & 14.234 & 11.539 & 9.773 & 7.875 & 8.834 & 12.740 & 22.018 & 21.987 & 21.482 & $-19,18$ \\
\hline P./N.* & 15.562 & 5.887 & 7.285 & 5.661 & 5.346 & 4.065 & 4.958 & 8.343 & 16.538 & 14.106 & 15.989 & 2,74 \\
\hline Uvas & 28.733 & 8.461 & 10.136 & 6.080 & 7.166 & 5.083 & 4.513 & 6.591 & 12.811 & 14.961 & 14.849 & $-48,32$ \\
\hline Quivi & 14.991 & 7.905 & 8.736 & 6.100 & 5.306 & 3.462 & 4.938 & 6.716 & 7.679 & 9.030 & 10.441 & $-30,35$ \\
\hline Cereja & 4.957 & 3.391 & 4.164 & 3.424 & 2.571 & 1.904 & 3.872 & 5.424 & 5.620 & 8.362 & 8.545 & 72,38 \\
\hline Caqui & 2.236 & 656 & 1.595 & 343 & 141 & 137 & 202 & 218 & 278 & 411 & 527 & $-76,43$ \\
\hline Dam.* & 685 & 213 & 325 & 222 & 127 & 142 & 194 & 246 & 410 & 483 & 377 & $-44,96$ \\
\hline Marm.* & 62 & 35 & 38 & 42 & 12 & 16 & 39 & 46 & 110 & 44 & 79 & 27,42 \\
\hline Framb. ${ }^{*}$ & 53 & 11 & 9 & 3 & 5 & 1 & 5 & 30 & 52 & 36 & 52 & $-1,89$ \\
\hline Total & 223.113 & 118.547 & 127.095 & 112.164 & 83.160 & 67.678 & 90.038 & 124.414 & 202.858 & 209.972 & 241.084 & 8,05 \\
\hline
\end{tabular}

*P./N.: pêssego/nectarina; Dam.: damasco; Marm.: marmelo; Framb.: framboesa e; Var.: variação.

\section{CONSIDERAÇÕES FINAIS}

O desenvolvimento de novas tecnologias e o domínio sobre as técnicas de cultivo de plantas frutíferas de clima temperado possibilitaram que $o$ Brasil passasse de grande importador para exportador de frutas no período de 1999 a 2009. Isto demonstra que com o apoio e o incentivo públicos, é possível aproveitar o potencial de clima e solo existente no País para aumentar a diversificação de cultivos e atender à demanda crescente por clima temperado para atender ao mercado interno e às exportações. A exploração destas frutíferas, pela sua ampla distribuição em vários estados e regiões, continua sendo muito importante na economia destes locais e base para a sustentação de milhares de famílias. A tendência é que o Brasil continue a especializar a sua produção em termos de uvas de mesa sem sementes para atender ao mercado internacional nas regiões quentes e que, no Sul, aumente a área cultivada de uvas viníferas em detrimento ao cultivo de uvas americanas e híbridos. Continue o crescimento no cultivo e produção de maçã, ameixa, caqui, quivi e pequenas frutas, ao passo que, em relação ao pessegueiro, a tendência é diminuir a área cultivada com frutas para indústria e aumentar o cultivo de frutas para mesa; os cultivos de pereira dependem do surgimento de novas cultivares e de trabalhos de pesquisa com o manejo da planta que assegurem a produção contínua desta espécie em locais de invernos com grande oscilação de temperatura. Deverá ocorrer estabilidade de cultivo com a figueira e diminuição ainda maior do cultivo de marmeleiro. Esse quadro geral poderá ser modificado, dependendo de parcerias que possam ser feitas com importadores para complementar a produção entre os dois hemisférios.

\section{REFERÊNCIAS}

ANTUNES, L. E. C.; TREVISAN, R.; PEREIRA, I. S. Produção de Amora-preta. In: SEMINÁRIO BRASILEIRO SOBRE PEQUENAS FRUTAS, 4., 2007, Vacaria. Anais... Bento Gonçalves: Embrapa Uva e Vinho, 2007. v.1, p.65-71.

ANUÁRIO BRASILEIRO DE FRUTICULTURA 2010. Santa Cruz do Sul: Editora Gazeta, 2010. 129 p.

BUAINAIN, A. M.; BATALHA, M. O. Cadeia produtiva de frutas. Brasília : IICA/MAPA/SPA, 2007. v.7, 102 p. 
FAO. FAOSTAT: production-crops. Disponível em: $<$ http://faostat.fao.org/site/567/DesktopDefault. aspx?PageID=567\#ancor $>$. Acesso em: 06 jun. 2011.

IBGE. Censo agropecuário 2009: lavoura permanente e temporária. Disponível em: <http:// http:// www.ibge.gov.br/estadosat/perfil.php?sigla $=\mathrm{rs}>$. Acesso em: 6 jun. 2011.
SILVEIRA, N.G.Á.; VARGAS, P.N.; ROSA, C.S. Teor de polifenóis e composição química do mirtilo do grupo highbush. Alimentos e Nutrição, Araraquara, v.18, n.4, p.365- 370, 2007. 